\title{
ENABLING RESILIENCE: SHIFTING THE INTERGENERATIONAL CAREER EXPECTATIONS OF SOUTH AFRICANS CHALLENGED BY STRUCTURAL DISADVANTAGE
}

\author{
L. C. Theron \\ Optentia Research Focus Area \\ North-West University, Vanderbijlpark Campus \\ Vanderbijlpark, South Africa \\ e-mail: Linda.Theron@nwu.ac.za
}

\section{ABSTRACT}

South African adults who are challenged by structural disadvantage typically urge the younger generation to aspire toward investment in academic education that will potentiate a lucrative career. Young people are likely to be influenced and guided by such intergenerational social expectations, particularly when their choices are not moderated by career counselling interventions. This process is inherently dangerous, however, when structural impediments obstruct the likelihood of young people's achievement of what was anticipated. Accordingly, I use this position paper to sensitize career counsellors as to how narrow intergenerational career expectations are likely, in challenging the resilience of young people in disadvantaged communities, to raise the odds against their success, and to galvanise career counsellors toward lowering these odds. In particular, I propose that career counsellors envisage disadvantaged communities as their clients, and facilitate a shift in career knowledge and intergenerational career expectations.

Keywords: resilience; career counselling; intergenerational career expectations; disadvantaged communities; social ecology; changing the odds

Resilience, or how well young people adjust to adverse life circumstances, is an intergenerational, socially determined process (De Jong et al. 2015). This means that young people cannot be held solely accountable for how they respond to challenging life-worlds (Ungar 2011). Instead, social ecological stakeholders (such as parents, teachers, practitioners and others service providers, community and cultural leaders, and policy makers) are crucially co-responsible for young people’s achievement of positive life outcomes (Masten 2014; Ungar 2013). They have a duty to provide young people with the resources necessary to do well in life as well as a duty to advocate for life-worlds that are less likely to put young people at risk for negative life outcomes. Put differently, social ecological stakeholders must proactively concern themselves with 'changing the odds' (Seccombe 2002, 384) that threaten the wellbeing of 
young people. Some resilience researchers (e.g., Hart 2015) contend that lessening adversity is likely to be more meaningful for young people's mental health and wellbeing than providing young people with relevant resources.

Purposefully altering the odds that predict negative life outcomes is, perhaps, even more crucial when these odds relate to structural disadvantage. Structural disadvantage refers to tangible and/or systemic barriers that set people up for negative life outcomes and over which individuals have very little control (for a detailed definition see VanderPlaat 2015; Young 2015). In South African parlance, and also as used in this article, being challenged by structural disadvantage is associated with a lack of privilege (compared with the minority of more privileged South Africans whose lives are not complicated by structural barriers, primarily because they are systemically advantaged). Typically, structural barriers are cumulative. For example, a black young woman who grows up in a poor, single-parent family in a rural, resource-poor township in South Africa is likely, amongst other disadvantages, to experience inferior schooling, the lack of available caregivers, and crime/violence, along with racial/classed/gendered stereotyping and marginalisation that will further complicate how she negotiates her life path. These multiple, co-occurring risks will compound her chances of beating the odds that are stacked against her, particularly if social ecological actors fail to intervene.

Accordingly, in this position paper I assert that career counsellors are social ecological actors who are particularly relevant to the resilience processes of South African young people who are challenged by structural disadvantage. I base this assertion on the understanding that resilience processes and career ambitions intertwine (Theron 2015; Theron, Liebenberg and Malindi 2014). Practicable career aspirations are grounded in informed career choices and knowledge of the multiple demands of a $21^{\text {st }}$ century labour market (Maree 2010; Savickas 2012a). This makes career counsellors indispensable to young people's realisation of their career aspirations, and to sustained resilience processes. But, as argued in this position paper, career counsellors also need to actively and proactively reduce the risk of intergenerational career-related expectations, given the potential of social expectations to heighten the vulnerability of young people living marginalised lives (Panter-Brick 2015). Essentially, therefore, this position paper rests on a social ecological or systems approach to resilience (see Masten 2014; Ungar 2011). Accordingly, it emphasises what social ecological actors (e.g., career counsellors) could/should do to enable young people to achieve functional outcomes, and it de-emphasises young people's contributions to this process.

I build the argument underpinning this thesis in the following order. First, I remind readers 
that ambitious career aspirations relate to South Africa's apartheid history. This calls for career counsellor sensitivity. Second, I describe the importance to resilience of a positive future orientation, and document that when young people are challenged by structural disadvantage, their resilience process is intertwined with career aspirations. As illustrated by my use of examples from South Africa and beyond, this appears to be a local and global phenomenon that is fuelled by intergenerational examples and accounts - both explicit and implicit. Third, I question the potential for straightforward accomplishment of career aspirations by South African young people who are members of disadvantaged marginalised communities. My concern relates to the perfunctory of career counselling opportunities, if they exist at all, in disadvantaged communities (Maree 2013; Tebele, Nel and Dlamini 2015), as well as to unsatisfactory school and tertiary education opportunities (Badat and Sayed 2014). Taking these obstacles into account, I problematize the non-critical perpetuation of resilience explanations that foreground career aspirations. In response to these, I conclude this position paper by proposing a fresh approach to career counselling that is likely to enable the resilience of South African young people who are challenged by structural disadvantage.

\section{EXPLAINING THE SOUTH AFRICAN EMPHASIS ON EDUCATION AND AMBITIOUS CAREERS}

Why do South African adults who are challenged by structural disadvantage typically expect the members of younger generations to invest in education and achieve skilled or professional occupations, and why are many South African young people desperate to realise these expectations? Such desperation is illustrated, for example, in the 2012 incident at the University of Johannesburg in which a woman was killed and 17 people injured in a stampede to enrol for the academic year (Nkomo, Warchal and Tshikovhi 2015). Part of the answer to both questions lies in South Africa's colonial and apartheid past.

Prior to 1994, quality school and university education processes and outcomes were inaccessible to the majority of South African learners (i.e., young black people). This was a direct result of the inequitable, racially-based education system that obstructed equal education opportunities for all (Badat and Sayed 2014). As a consequence, career choice was a misnomer and disenfranchised South Africans (i.e., the black majority) were, for the most part, forced into un- or semi-skilled employment for paltry wages (Phasha 2010). Inequitable education was, therefore, 'a way of institutionalizing inferiority' (Mandela 1995, 195). No wonder then that post-1994 adults urge the next generation to optimise educational opportunities and aim for the careers that they and their parents and grand-parents were denied. 
While economic advancement is crucial to the wellbeing of people who have been structurally disadvantaged for generations, academic/tertiary education and subsequent professional career pathways are not the only means of securing economic inclusion. One such alternative is a career path based on technical and vocational education and training (TVET) (Diale 2015). However, in South Africa, colleges offering TVET qualifications are not popular choices (Nkomo et al. 2015). This is, in all likelihood, linked to the inequitable colonial and apartheid education practices (referred to above) which effectively barred academic career pathways for the majority of South Africans; TVET is associated with the non-academic education tracks that were scripted for black South Africans (Perry 2009). There are similar responses elsewhere in post-colonial Africa. For example, following a study of TVET trends in seven previously colonised African countries, Oketch (2007) concluded that, in general, TVET is negatively regarded and that parents would rather make sacrifices (e.g., sell off their meagre belongings) to support their children to achieve an academic education. As suggested above, this negativity is related in part to the introduction of TVET to Africa by colonial education systems in ways that reinforced the notion that it was an inferior form of education (Oketch 2014). Consequently, in opposition to this, career paths related to academic trajectories and subsequent professional qualifications are widely preferred, and expected. Embedded in these expectations are hopes of a transformed destiny.

\section{RESILIENCE, HOPE, AND PROFITABLE CAREER ASPIRATIONS}

When current life circumstances are bleak the belief that the future will be better is a driver of resilience (Maholmes 2014; Masten 2014). Being oriented to the future enables the accommodation of a distressing present, partly because of the implication that the status quo will be transformed as long as certain goals are achieved (Harley and Hunn 2015). To this end, investment in education and career aspirations are central. For example, in her study with 16 African American adolescents from an impoverished community in Ohio, USA, Harley (2011, 105) documented a 'Gonna make it mentality' as being integral to these young people's resilience. They were adamant that they would achieve education and career goals and, in so doing, beat the odds that were stacked against them. Ozdemir and Hacifazlioglu (2008) noted similar trends among young people from economically disadvantaged contexts in Turkey. They preferred study directions that would lead to lucrative careers (e.g., engineering) unlike those from privileged backgrounds who were more likely to opt for art-oriented/social science careers that do not potentiate financial reward.

South African studies of resilience report comparable results. Hope and goal-directed 
behaviour are integral to what enables the resilience of South African young people (see, for example, Ebersöhn and Maree 2006; Malindi and Machenjedze 2012; Phasha 2010; Theron 2015; Theron and Theron 2010, 2013; Van Breda 2015). Completion of Grade 12 and a subsequent tertiary qualification which opens doors to a profitable career are fundamental to many young South Africans' dreams of a transformed future, particularly among those from marginalised communities (Dass-Brailsford 2005; Phasha 2010; Tebele et al. 2015; Theron 2015; Theron and Phasha 2015). For example, Tebele et al. (2015) reported that high-paying careers drove career choices among their participants who were black learners from a high school in disadvantaged rural Kwazulu-Natal. One young woman reportedly said: ' $\mathrm{I}$ [want] ... to be paid a huge salary' (Tebele et al. 2015, 259).

Similarly, in the Pathways to Resilience Study, South Africa, young people (aged 12-19) living in structurally disadvantaged communities in the rural Free State repeatedly reported that their continued accommodation of co-occurring adversities (such as poor health, violence, and poverty) was rooted in their hopes of upgraded life prospects (Theron 2015; Theron et al. 2014). To this end, they valorised education for its potential to facilitate white-collar or professional employment opportunities. For instance, a 14-year-old girl commented, 'School helps me because if I'm not educated I'm not going to find a job, like being a teacher or a doctor. I'm only going to find a piece-job’ (Theron 2015, 17). A piece-job, or temporary unskilled employment, was synonymous with a perpetuation of the socio-economic disadvantage that characterised the lives of participants' parents whose inferior education, enforced during the years of apartheid (see Badat and Sayed 2014), generally precluded opportunities for skilled employment and/or diploma- or degree-linked careers.

In many cases, Pathways participants associated upward mobility with an opportunity to benefit struggling parents or communities. As a 17-year-old young woman put it, '[O]ne day my mother will eat my money [benefit from my schooling]' (Theron 2015, 17). Another participant, a 14-year-old girl living with both parents in a rural township, explained that her resilience was embedded in her plan to 'study and finish school and go to university ...'. She went on to say, '[A]nd then after, I get a job and my life goes far! I want to be a social worker. I want to help other children that have no parents and to buy some food and clothes for them.' (Theron and Theron 2014a). Mhlongo and O’Neill (2013) theorise that for young people from collectivist cultures (such as the traditionally African communities from which the Pathways participants came), the duty to contribute influences career choice. Choices are predicated on the remuneration potential of a career, with its potential to facilitate a social contribution; young people want to support their families and uplift their communities. 
The belief that education and better-paying employment is a crucial aspiration is voiced by parents and adult community members too, and particularly by adults in less privileged communities. For example, a study with 31 lower middle-class families in the United States of America provided proof that parents associated college education with upward mobility, even though these same parents could ill afford to finance their children's college education (Napolitano, Pacholok and Furstenberg 2014). One mother said, 'I want them to go to college because I don’t want them to have a hard life' (Napolitano et al. 2014, 1211). Similarly, Mhlongo and O’Neill's (2013) study with first-year black students from disadvantaged South African backgrounds showed that a student's choice of what to study was often informed by ambitious careers recommended by their parents. In fact, in under-privileged contexts, the hopes of parents in relation to their children's futures shape the aspirations of these young people more significantly than such hopes do in privileged contexts. Schoon and Bynner (2003) reported that young British men from disadvantaged communities were more likely to aspire toward education and upward mobility when their parents expected this, than did young British men from privileged families. Likewise, a study that linked data generated by 9717 British 16year-olds to adult outcomes at age 33 showed that parental aspirations, in particular, were a significant predictor of positive outcomes for young people from disadvantaged communities (Schoon, Parsons and Sacker 2004).

For young people to become aware of parental and other adult hopes, adults need to articulate their expectations. In studies of resilience among Chinese adolescents (see Tian and Wang 2015) and Inuit youth (see Liebenberg, Ikeda and Wood 2015), parents, grandparents, and teachers told young people how important it was for them to pursue academic qualifications that would potentiate good employment opportunities. Similarly, resilience-focused South African studies relate how parents, siblings and other kin, teachers, and other adults explicitly communicated the importance of education and professional career aspirations (e.g., DassBrailsford 2005; Phasha 2010; Theron, Liebenberg and Malindi 2014; Theron and Theron 2013, 2014b). A university student who participated in the resilience-focused study by DassBrailsford (2005) referred to her disadvantaged community's overt endorsement of her investment in tertiary education. She said, 'My community sees that I am doing the right thing ... mothers tell me their children can look at me as a role model when I graduate' $(2005,583)$.

The importance of career aspirations and associated changes in fortune was also implicitly communicated via the example of older siblings (e.g., Theron and Phasha 2015; Theron and Theron 2013) or teachers who came from similarly disadvantaged circumstances (e.g., DassBrailsford 2005; Theron and Theron 2013, 2014b). A 19-year-old undergraduate attributed his 
aspirations to the example of his brothers when he said, 'We were amongst the poorest in my community. But things improved a bit coz now my brothers are educated. ... they sort of built this thing of motivation within the family, because once the first one graduated, we all had to follow' (Theron and Theron 2013, 402).

In addition to coming from role-models, expectations are implicitly communicated via the discourse around resilience. A case in point involves the stories of community-based adults who were asked to contribute to the Pathways to Resilience Study, South Africa, by explaining local understandings of resilience. Implicit in their accounts are themes of investment in education and subsequent career success that supports personal and familial upliftment. A 35year-old male teacher wrote this story of a boy whom he considered to be resilient:

His mother passed away when he was still very young (around the age of six). The father was unemployed and depended on his mother's pension. The boy grew up with his aunt who was also struggling because she was unemployed. Despite the situation, the boy went to school, often without uniform and studied until he completed his primary and secondary school education. Through the NASFAS bursary, the boy studied chemical engineering. The boy is now working for a big private company and has built a very big house for his father, who was staying in an RDP house, he bought himself a nice car, and has built his aunt a bigger house (Theron and Theron 2014a).

Similarly, a 43-year-old businessman reflected on what enabled the resilience of a young man with whom he was acquainted. He explained:

His mother passed on in his early childhood - when he was 3 years old. His grandmother saw to his upbringing. His father was crippled in about the same period which aggravated his situation. They grew up being beggars because there was no income except the small pension money his granny received. His granny wanted him to grow and one day emancipate his family from the abject poverty. He duly obliged and embraced education ... He made school a necessary tool to liberate him from poverty and ignorance ... he grew up selling fruits to survive and often did gardens for survival and payment of school fees. [Pointing to a drawing he made of a young man in a graduation gown, labelled 'educated and being a manager'] The picture depicts the breakaway from poverty and suffering. A better life has arrived (Theron and Theron 2014a).

In summary, adults explicitly and implicitly communicate upward mobility ideals and link these to academic education and white collar careers. Via stories of resilience and the communication of admiration, they reinforce young people's enactment of their expectations. In doing so, they illustrate the understanding that career constructions are 'structured by the community and then imposed on individuals in the form of social expectations’' (Savickas 2012b, 231-232).

\section{BARRIERS TO ACHIEVING CAREER ASPIRATIONS AND IMPLICATIONS FOR RESILIENCE}


While the above intergenerational expectations make sense, given the structural violence and unequal education and career opportunities of South Africa's colonial and apartheid past, it is necessary to question how realisable the expectations are that are being imposed on, and internalised by, young people who are challenged by structural disadvantage. Continued education barriers and superficial career counselling opportunities prompt this concern. In the sub-sections below I summarise these barriers before expanding on how they jeopardize career aspirations and sustained resilience.

\section{Education barriers to realising career aspirations}

Despite the worthy ideals of post-1994 education policies and increased government expenditure on education, the colonial and apartheid legacies of structural inequality (and concomitant inequity) have continued to mar the quality of education for the majority of South African learners (Badat and Sayed 2014; Donohue and Bornman 2014; Modisaotsile 2012). Accordingly, education is generally characterised inter alia by inferior teaching, disillusioned and/or apathetic teachers, overfull and under-resourced classrooms, and chronically unsatisfactory exam results that point to substandard literacy and numeracy (Donohue and Bornman 2014; Mayosi et al. 2012; Modisaotsile 2012). The aforementioned problems are disproportionately characteristic of schools serving racially, geographically, and economically marginalised communities (Mayosi et al. 2012). Consequently, the children of the workingclass (i.e., those who earn wages for manual or industrial labour and, often more typically, the working poor) and of the rural poor are least served educationally (Badat and Sayed 2014). An inferior educational foundation confounds successful transitioning to university as well as the mastery of course material, and might account for the high attrition rates of first-year students (Maree, Fletcher and Sommerville 2011).

Career aspirations are also foiled by continued inequitable access to tertiary institutions. Currently, historically disadvantaged young people are least likely to participate in higher education and most likely to be made vulnerable by colonialist and other institutional cultures that exclude and alienate young people who come from marginalised life-worlds (Badat and Sayed 2014; Nkosi 2015). Additionally, because many of these young people are the first in their families to attend university, they are ill-prepared for what tertiary education entails and/or, given their families' lack of relevant experience, they lack family guidance and support (Mhlongo and O’Neill 2013; Theron and Theron 2013). Furthermore, tertiary education does not guarantee employment (sustained or otherwise), particularly for women (Stats SA 2012). Nor does it necessarily equip young people to master the multiple challenges and dynamism of 
the $21^{\text {st }}$ century employment landscape (Savickas 2012a). The sad reality is that young people between the ages of 15-24 are disproportionately represented in South Africa's unemployment rate of 25 per cent (World Bank 2015).

\section{Counselling barriers to realising career aspirations}

Despite the documented importance of career counselling for all (e.g., Maree 2010, 2013; Savickas 2012a), it is mostly those young people whose parents/caregivers are aware of the value of professional career counselling, and can afford it, who are assisted to make informed career decisions. Typically, in South Africa, these professionals, in being from privileged backgrounds, are disconnected from the life experiences and structural hurdles of young people from disadvantaged groups, and they use approaches better suited to western adolescents (Ebersöhn 2012; Maree 2010; Maree, Ebersöhn and Molepo 2006). At school level, education departments generally no longer support psychometric assessment of learner aptitude for specific careers (Maree et al. 2006). While traditional psychometric evaluation is not currently considered an optimal approach to career education and counselling (see Maree 2013; Morgan 2010), the cessation of departmental support of informed career choices constrains the career decisions of young people whose parents/caregivers cannot afford professional career counselling for them. As I go on to explain, these young people are then reliant on curriculumbased opportunities to learn about career options.

The South African 2011 Curriculum and Policy Statements (CAPS) stipulate that the Life Orientation (LO) curriculum must include career education for children in grades 7 to 12 (Hay 2014). The reality, however, is that school-based career education does not materialise as prescribed by policy (Tebele et al. 2015). Part of this neglect relates to inadequate time allocation to career education, as well as limited or no opportunity for LO teachers to provide individual career education/counselling to learners (Smit, Wood and Neethling 2015). As Hay (2014, 402) notes: 'Teaching career education in a big group is not effective for a number of learners'. Additionally, LO teachers are advised to focus career-related lesson content on nonhigher education careers and semi-skilled career options, given the reality that fewer than 80 per cent of matriculants participate in higher education (Hay 2014). Still, it is unclear whether teachers heed this advice. Therefore, it is not surprising that black learners from a high school in rural Kwazulu-Natal reported that their career awareness was limited to the realm of subject choice only, and that career-counselling was practically non-existent in their school (Tebele et al. 2015). In summary, despite the official inclusion of career education in the LO curriculum, meaningful career counselling is typically not available to young people in disadvantaged 
contexts (Maree 2013). This absence of meaningful career counselling dooms the career aspirations of young people already challenged by structural risks (Mhlongo and O’Neill 2013).

\section{Barrier-related implications for resilience}

Clearly, the factors outlined above are likely to complicate how successfully young people from structurally disempowered life-worlds achieve what is anticipated, particularly when career ambitions are predicated on the attainment of tertiary education qualifications. Struggling to achieve what is expected and/or hoped for subverts the resilience-enabling power traditionally associated with future-oriented goals and hopes (Masten 2014). Panter-Brick and Eggerman (2012, 383) warn about the dangers of what is known as social entrapment - the fate of young people who experience social expectations as both obligatory and onerous. This typically happens when structural barriers thwart young people's realisation of social expectations (Panter-Brick 2015). For example, Afghan young people are caught up in the widely endorsed cultural expectation that they secure profitable employment; failure to do so is associated with continued hardship for their families. However, in conflict-riddled Afghanistan achieving postschool employment is challenging. The pressure to fulfil this obligation has been shown to have undermined the protective value of career aspirations and attachment to family (Panter-Brick and Eggerman 2012).

Similarly, young South African people who are in the process of enacting the social expectation that they achieve the goal of an academic tertiary education and provide for their families, report experiences suggestive of such social entrapment. For instance, Mhlongo and O’Neill (2013) commented on how family needs take precedence over individual inclinations. In this regard, one of their participants, in reporting how responsibility to family curtailed personal choice, said, 'It hurts me because others suggested that I take one year or two year courses, things that take little time, hurry up and study and get a job; so I can say family finances are a negative effect' (O’Neill 2013, 960). Similarly, a 24-year-old graduate who contributed to the Pathways study lamented his lack of freedom to choose to follow his own career aspirations which were artistic and would not enable financial provision. He said:

It's very difficult for a young black person, coz you know I'm gonna achieve 1, 2 and 3, but it's gonna be crushed coz my parents want me to do a degree - the situation at home is not allowing for me to pursue my own goals. In the end, you find that you are not happy yourself, but the entire family is happy because of the efforts that, that you made. You become glorified at home: 'We can eat because of you.’ But, your frustrations are with you every night .... (Theron et al. 2015)

In short, given the above, it is questionable how young people's resilience can be sustained in 
the course of their unassisted enactment of intergenerational career expectations. Such doubt is probably even more relevant in cases where obstacles such as inadequate Grade 12 results or funding constraints prevent young people from acting on the prevailing social expectation to gain an academic qualification and secure profitable employment (Theron 2015). Accordingly, as proposed below, career counsellors have a significant imperative.

\section{'CHANGING THE ODDS': RE-ENVISIONING CAREER COUNSELLING}

As noted in the introduction of this position paper, social ecologies should engage in proactively 'changing the odds' (Seccombe 2002, 384) that obstruct the wellbeing of young people. Supplying young people with resources that enable 'beating the odds' (Seccombe 2002, 384) is important, but pre-empting and preventing or lessening such odds are even more important (Hart 2015). Thus, South African career counsellors have a dual task.

First, they should make contemporary, culturally relevant career interventions (as documented by Ebersöhn 2012; Maree 2013; Maree et al. 2006; Morgan 2010; Savickas 2012a) available to young people in disadvantaged communities. In this regard, career counsellors will have to advocate for creative practices such as lobbying the Health Professions Council of South Africa to mandate that a portion of relevant psychology internships (e.g., educational psychology, as proposed by Mhlongo and O’Neill 2013) is reserved for career counselling services in disadvantaged communities. Psychology-linked academics who are research active could choose to engage in university-community partnerships that enable young people in disadvantaged communities to access career counselling, as modelled, for example, in the Flourishing Learning Youth project (see Ebersöhn 2015). Career counsellors will also need to consider volunteering for career counselling services in disadvantaged communities, preferably in collaboration with non-governmental organisations that are already actively providing career counselling services to young people in disadvantaged communities (for NGO examples, see Mahlangu 2011).

Second, and probably more crucially, South African career counsellors need to make it their business to disrupt the prevailing rhetoric linking education and concomitant professional career status to economic advancement and resilience more generally. Given the abysmal attrition of first year South African university students who are challenged by structural disadvantage (Maree et al. 2011; Osman 2015), allowing intergenerational, clichéd expectations relating to profitable careers to go unchecked will worsen the structural odds already stacked against young people from disadvantaged communities. This does not mean that career counsellors should deny the value of education and professional careers to economic inclusion, 
but, rather, that they should expand recognition of vocational, technical, and entrepreneurial career paths that will enable economic independence. Put differently, career counsellors need to envisage disadvantaged communities as their clients and purposefully broaden community knowledge of diverse career paths. In so doing, they accept responsibility for moderating the 'history of job discrimination [that] lingers in the collective psyche of many black South Africans' (Nkomo et al. 2015). Encouraging a revitalised understanding of the multiplicity of employment trajectories changes the odds of young people's entrapment in narrow, stereotypical career expectations.

Because of the significance of parental aspirations to, and teacher influences on, the career choices of young people in underprivileged life-worlds (e.g., Dass-Brailsford 2005; Mhlongo and O’Neill 2013; Schoon and Bynner 2003; Schoon et al. 2004; Theron and Theron 2013, 2014b), educating parents/parent-figures, teachers, and others is a critical component of such community engagement; such education must be about more than instilling appreciation for the importance of career counselling as recommended by Ozdemir and Hacifazlioglu (2008). Even though facts about scarce skills are important, career education must go beyond providing facts relating to South Africa's need for artisans and other skilled workers (Steyn 2015); its focus should be on extending community awareness of the existence of myriad and diverse career pathways to economic inclusion, making the links between scarce skills and economic security apparent, and encouraging advancement of less timeworn intergenerational career messages. To this end, community education interventions need to revisit TVET sensitively, given its historic connotations, as an alternative pathway, along with other viable career opportunities that are not grounded in higher education qualifications. These interventions need to celebrate entrepreneurial opportunities, and they should encourage hope and agency (Smit et al. 2015).

Since South African career counsellors represent privilege (Ebersöhn 2012; Maree 2010; Maree et al. 2006), it might be more practicable if they facilitate (instead of personally provide) community career education given the existing concerns around power differentials and other disconnects between them and the young people who need sound advice. This could entail inviting a variety of locals (or nationals with whom community members will identify) that represent diverse career options such as, for example, construction, production and manufacturing, the hospitality industry, transportation, real estate and other less-traditional business options, including those associated with the military, to share their career story with community members. This sharing could include details about the requisite training/education, the necessary skill sets, as well as the highlights and the challenges of such career options. Including younger people who have succeeded in securing employment that is meaningful but 
that deviates from the expected tertiary education and high-paying career stereotype will extend the repertoire of role models that can be drawn on for inspiration. In this sense, career counsellors and community members would be co-producing community-focused career interventions that creatively enable community exposure to the dynamic variety of the contemporary world of work and that, at least potentially, nurture a more positive collective attitude to careers that are not based on the attainment of higher education. Hay (2014) urges teachers to facilitate learner access to the world of work; inviting the world of work to educate the community augments this in ways that potentiate a shift in stereotypical career expectations.

As part of the community career education agenda, insight into how best to offer support to first generation college/university students is important (Perry 2009). It would be helpful for parents and others to understand that showing interest - even though they have no personal experience of tertiary education - lessens the pressure and isolation first generation students experience. For example, a participant in the study by Mhlongo and O’Neill (2013) bemoaned the fact that not a single family or community member had enquired about what it was like to be at university or asked about its associated difficulties or triumphs. In contrast to this student's experience, when family or community members showed supportive interest, young people were buoyed (Dass-Brailsford 2005; Mhlongo and O’Neill 2013). Teachers in particular need to be sensitised as to how they can support first generation college/university students to anticipate the demands, challenges, and joys of tertiary education. South African research shows that when teachers are willing to share first-hand experience of the challenges of adjusting to university/college and how they overcame these, their personal stories of adjustment strengthen young people's resilience to the challenges of being a first generation student (Theron and Theron 2014b).

In conclusion, by advocating for and practically contributing to career counselling opportunities for young people challenged by structural disadvantage, and by educating their communities toward revitalised and extended intergenerational career convictions, career counsellors are likely to be change agents and champions of resilience. The value of this role in post-1994 South Africa, in which historically marginalised communities generally continue to be structurally violated, is intuitive. Still, as previously suggested for novel career counselling approaches (Morgan 2010; Perry 2009), the merits and practicalities of heightening whole communities' awareness of $21^{\text {st }}$ century career opportunities - as part of championing the resilience of marginalised young people - requires empirical verification. This will include: (i) training career counsellors to recognise the diversity of $21^{\text {st }}$ century career paths; (ii) establishing community-practitioner alliances (including association with diverse career 
role-models) and co-producing community-focused career-education interventions; (iii) sourcing funding; (iv) piloting the aforementioned and assessing and documenting their impact. Essentially, whether practitioner- or researcher-driven or both, investigation of how best to extend career counselling agendas in ways that will include, and enable, the adults who shape young people's career choices, is both imperative and overdue.

\section{ACKNOWLEDGEMENT}

I thank the National Research Foundation (NRF), South Africa for Incentive Funding (Grant: IFR2011041100058) that facilitated the work underpinning this article. The NRF cannot be held responsible for the contents of this article.

\section{REFERENCES}

Badat, S. and Y. Sayed. 2014. Post-1994 South African education the challenge of social justice. The ANNALS of the American Academy of Political and Social Science 652(1): 127-148.

Dass-Brailsford, P. 2005. Exploring resilience: Academic achievement among disadvantaged black youth in South Africa. South African Journal of Psychology 35(3): 574-591.

De Jong, J. T., L. H. Berckmoes, B. A. Kohrt, S. J. Song, W. A. Tol and R. Reis. 2015. A public health approach to address the mental health burden of youth in situations of political violence and humanitarian emergencies. Current Psychiatry Reports 17(7): 1-10.

Diale, T. 2015. Advocating the need to introduce technical vocational education and training (TVET) at South African primary schools. Paper presented at the $21^{\text {st }}$ South African Psychology Conference, Johannesburg, September.

Donohue, D. and J. Bornman. 2014. The challenges of realising inclusive education in South Africa. South African Journal of Education 34(2): 1-14.

Ebersöhn, L. 2012. Imagining career resilience research and training from an indigenous knowledge production perspective. South African Journal of Higher Education 4th Annual South African Technology Network Conference 2011: Curriculum transformation at universities of technology: Towards development of new generation universities: Special Issue 26(4): 800-812. Sabinet Online.

Ebersöhn, L. 2015. Making sense of place in school-based intervention research. Contemporary Educational Psychology 40: 121-130.

Ebersöhn, L. and J. G. Maree. 2006. Demonstrating resilience in an HIV and AIDS context: An emotional intelligence perspective. Gifted Education International 22(1): 14-30.

Harley, D. M. 2011. Perceptions of hope and hopelessness among low-income African American adolescents. Doctoral dissertation, The Ohio State University.

Harley, D. and V. Hunn. 2015. Utilization of photo voice to explore hope and spirituality among lowincome African American adolescents. Child and Adolescent Social Work Journal 32(1): 3-15.

Hart, A. 2015. Head Start in action: Building emotional resilience in children and young people in local communities across England. Paper presented at Pathways to Resilience III: Beyond Nature vs. Nurture, Halifax, Canada, June.

Hay, J. 2014. Careers and the world of work. In Life orientation for South African teachers, ed. M. Nel, 393-410. Pretoria. Van Schaik.

Liebenberg, L., J. Ikeda and M. Wood. 2015. 'It's just part of my culture’: Understanding language and land in the resilience process of aboriginal youth. In Youth resilience and culture: Commonalities 
and Complexities, ed. L. C. Theron, L. Liebenberg and M. Ungar, 105-116. Dordrecht. Springer.

Mahlangu, V. 2011. Dilemma of school districts in managing career counseling in South Africa. Journal of Emerging Trends in Educational Research and Policy Studies 2(4): 239-245.

Maholmes, V. 2014. Fostering resilience and well-being in children and families in poverty. Why hope still matters. New York. Oxford Press.

Malindi, J. M. and N. Machenjedze. 2012. The role of school engagement in strengthening resilience among male street children. South African Journal of Psychology 42: 71-81.

Mandela, N. 1995. Long walk to freedom. London. Abacus.

Maree, J. G. 2010. Brief overview of the advancement of postmodern approaches to career counseling. Journal of Psychology in Africa 20(3): 361-367.

Maree, J. G. 2013. Counselling for career construction: Connecting life themes to construct life portraits: Turning pain into hope. Rotterdam. Springer.

Maree, K., L. Ebersöhn and M. Molepo. 2006. Administering narrative career counselling in a diverse setting: Trimming the sails to the wind. South African Journal of Education 26(1): 49-60.

Maree, J. G., L. Fletcher and J. Sommerville. 2011. Predicting success among prospective disadvantaged students in natural scientific fields. South African Journal of Higher Education 25: 1125-1139. http://search.sabinet.co.za.nwulib.nwu.ac.za/WebZ/AdvancedQuery?sessionid= $\quad$ 01-486911416000642 (accessed 2 July 2012).

Masten, A. S. 2014. Ordinary magic. Resilience in development. New York. Guilford Press.

Mayosi, B. M., J. E. Lawn, A. Van Niekerk, D. Bradshaw, S. S. A. Karim, H. M. Coovadia and Lancet South Africa team. 2012. Health in South Africa: Changes and challenges since 2009. The Lancet 380(9858): 2029-2043.

Mhlongo, Z. S. and V. C. O'Neill. 2013. Family influences on career decisions by black first-year UKZN students. South African Journal of Higher Education 27(4): 953-965.

Modisaotsile, B. M. 2012. The failing standard of basic education in South Africa. Africa Institute of South Africa 72.

Morgan, B. 2010. Career counselling in the 21st century: A reaction article. Journal of Psychology 20(3): 501-503.

Napolitano, L. J., S. Pacholok and F. F. Furstenberg. 2014. Educational aspirations, expectations, and realities for middle-income families. Journal of Family Issues 35(9): 1200-1226.

Nkomo, M., A. Warchal and N. Tshikovhi. 2015. History explains why black South Africans still mistrust vocational training. The Conversation, September 10. https://theconversation.com/ history-explains-why-black-south-africans-still-mistrust-vocational-training-46998 (accessed 11 November 2015).

Nkosi, B. 2015. This is the year varsities will transform Blade. Mail \& Guardian, May 4. http://mg.co.za/article/2015-05-14-this-is-the-year-varsities-will-transform-blade (accessed 3 June 2015).

Oketch, M. O. 2007. To vocationalise or not to vocationalise? Perspectives on current trends and issues in technical and vocational education and training (TVET) in Africa. International Journal of Educational Development 27(2): 220-234.

Oketch, M. 2014. Education policy, vocational training, and the youth in Sub-Saharan Africa, (WIDER Working Paper.) No. 2014/069. http://www.econstor.eu/bitstream/10419/97120/ 1/782364543.pdf (accessed 11 November 2015).

Osman, R. 2015. How South Africa can disrupt its deeply rooted educational inequality. The Conversation, October 6. https://theconversation.com/how-south-africa-can-disrupt-its-deeplyrooted-educational-inequality-48531 (accessed 1 February 2016).

Ozdemir, N. and O. Hacifazlioglu. 2008. Influence of family and environment on students' occupational choices and expectations of their prospective universities. Social Behavior and Personality 36(4): 
433-446.

Panter-Brick, C. 2015. Culture and resilience: Next steps for theory and practice. In Youth resilience and culture: Commonalities and complexities, ed. L. C. Theron, L. Liebenberg and M. Ungar, 233-244. Dordrecht: Springer.

Panter-Brick, C. and M. Eggerman. 2012. Understanding culture, resilience, and mental health: The production of hope. In The social ecology of resilience. A handbook of theory and practice, ed. M. Ungar, 369-386. New York: Springer.

Perry, J. C. 2009. Career counselling with secondary school-aged youth: Directions for theory, research, and practice. South African Journal of Higher Education 23(3): 482-504.

Phasha, T. N. 2010. Educational resilience among African survivors of child sexual abuse in South Africa. Journal of Black Studies 40(6): 1234-1253.

Savickas, M. L. 2012a. Life design: A paradigm for career intervention in the 21st century. Journal of Counseling \& Development 90(1): 13-19.

Savickas, M. L. 2012b. Toward a taxonomy of human strengths: Career. In Counseling psychology and optimal human functioning, ed. W. B. Walsh, 229-250. Third edition. New York. Routledge.

Schoon, I. and J. Bynner. 2003. Risk and resilience in the life course: Implications for interventions and social policies. Journal of Youth Studies 6(1): 21-31.

Schoon, I., S. Parsons and A. Sacker. 2004. Socioeconomic adversity, educational resilience, and subsequent levels of adult adaptation. Journal of Adolescent Research 19(4): 383-404.

Seccombe, K. 2002. 'Beating the odds' versus 'Changing the odds': Poverty, resilience, and family policy. Journal of Marriage and Family 64(2): 384-394.

Smit, S., L. Wood and M. Neethling. 2015. Helping learners think more hopefully about life after school: The usefulness of participatory visual strategies to make career education more contextually relevant. Perspectives in Education 33(3): 121-140.

Statistics South Africa. 2012. Gender statistics in South Africa, 2011. Pretoria: Statistics South Africa.

Steyn, L. 2015. SA's skills deficit has a negative effect on employment. Mail and Guardian, May 18. http://mg.co.za/article/2015-05-18-sas-skills-deficit-has-a-negative-effect-on-employment (accessed 11 November 2015).

Tebele, C., K. A. Nel and B. Dlamini. 2015. Career support needs of learners with historical disadvantage: An exploratory study. Journal of Psychology in Africa 25(3): 258-261.

Theron, L. C. 2015. Towards a culturally- and contextually-sensitive understanding of resilience: Privileging the voices of black, South African young people. Journal of Adolescent Research (online, ahead of print) doi: 10.1177/0743558415600072.

Theron, L. C., A. Bhana, D. Bottrell, A. Hart, L. McCubbin, C. Mphande and S. Reid. 2015. Case studies of 'waithood' and resilience-supporting responses from African and other inequitable contexts. Invited concurrent plenary panel, Pathways to Resilience III: Beyond Nature vs. Nurture, Halifax, Canada, June.

Theron, L. C., L. Liebenberg and M. J. Malindi. 2014. When schooling experiences are respectful of children’s rights: A pathway to resilience. School Psychology International 35(3): 253-265.

Theron, L. C. and N. Phasha. 2015. Cultural pathways to resilience: Opportunities and obstacles as recalled by black South African students. In Youth resilience and culture: Commonalities and complexities, eds. L. C. Theron. L. Liebenberg and M. Ungar, 51-66. Dordrecht. Springer.

Theron, L. C. and A. M. C. Theron. 2010. A critical review of studies of South African youth resilience, 1990-2008. South African Journal of Science 106(7/8). http://www.sajs.co.za (accessed 2 November 2015).

Theron, L. C. and A. M. C. Theron. 2013. Positive adjustment to poverty: How family communities encourage resilience in traditional African contexts. Culture \& Psychology 19(3): 391-41.

Theron, L. C. and A. M. C. Theron. 2014a. Facilitating youth resilience processes: Evidence-based 
guidelines for educational psychologists. Paper presented at the 28th International Congress of Applied Psychology, Paris, France, July.

Theron, L. and A. M. C. Theron. 2014b. Education services and resilience processes: Resilient black South African students' experiences. Child and Youth Services Review 47(3): 297-306.

Tian, G. and X. Wang. 2015. Cultural pathways to resilience: Informal social support of at-risk youth in China. In Youth resilience and culture: Commonalities and Complexities, eds. L. C. Theron, L. Liebenberg and M. Ungar, 93-104. Dordrecht. Springer.

Ungar, M. 2011. The social ecology of resilience: Addressing contextual and cultural ambiguity of a nascent construct. American Journal of Orthopsychiatry 81: 1-17.

Ungar, M. 2013. Resilience, trauma, context, and culture. Trauma, Violence, \& Abuse 14(3): 255-266.

Van Breda, A. D. 2015. A comparison of youth resilience across seven South African sites. Child \& Family Social Work (on-line, ahead of print) doi/10.1111/cfs.12222/epdf.

VanderPlaat, M. 2015. Activating the sociological imagination to explore the boundaries of resilience research and practice. School Psychology International (on-line, ahead of print) doi: 10.1177/0143034315615938.

Werner, E. E. 2013. What can we learn about resilience from large-scale longitudinal studies? In Handbook of resilience in children, eds. S. Goldstein and R. B. Brooks, 87-102. Second edition. New York. Springer.

World Bank. 2015. South Africa economic update: Jobs and South Africa's changing demographics. (South Africa economic update). Issue no. 7. Washington, D.C., World Bank Group. http://documents.worldbank.org/curated/en/2015/08/24910225/south-africa-economic-updatejobs-south-africa's-changing-demographics (accessed 11 November 2015).

Young, M. 2015. Work-family conflict in context: The impact of structural and perceived neighborhood disadvantage on work-family conflict. Social Science Research 50: 311-327. doi:10.1016/j.ssresearch.2014.12.001. 